CLINICAL STUDY

\title{
Testosterone, androgen receptor gene CAG repeat length, mood and behaviour in adolescent males
}

\author{
Hans Vermeersch, Guy T’Sjoen ${ }^{1}$, Jean Marc Kaufman ${ }^{1}$, John Vincke and Mieke Van Houtte \\ Department of Sociology, University of Ghent, Korte Meer 5, 9000 Ghent, Belgium and ${ }^{1}$ Department of Endocrinology, University Hospital Ghent, \\ 9000 Ghent, Belgium \\ (Correspondence should be addressed to H Vermeersch; Email: hans.vermeersch@ugent.be)
}

\begin{abstract}
Objectives: Androgen activity has been implicated in a range of traits and behaviours that have well-documented sex differences. However, the results of the studies on the relationship between testosterone and these traits and behaviours are inconsistent. This study has analyzed i) whether CAG repeat length, a presumed modulator of androgen receptor sensitivity, is associated with sex-dimorphic traits and behaviours (aggressive and non-aggressive risk-taking (ART and NART), dominance, depressive symptoms and self-esteem), and ii) whether CAG repeat length interacts with free testosterone (FT) with respect to these traits and behaviours.

Design and methods: Data obtained from a group of adolescent boys ( $n=301$; mean age: 14.4 years) were analyzed using multivariate general linear modelling (SPSS, Chicago, IL, USA 15.0).

Results: We found no direct correlation between CAG repeat length and dependent variables. We found significant interactions between CAG repeat length and testosterone, indicating that FT was more positively related to ART and NART with a shorter repeat length, and that an inverse association of FT with depressive symptoms and a positive association with self-esteem were stronger in boys with a longer CAG repeat length.

Conclusion: Our findings indicate the importance of studying FT and CAG repeat length simultaneously with respect to sex-dimorphic traits, taking into account the possible interactions between the two.
\end{abstract}

European Journal of Endocrinology 163 319-328

\section{Introduction}

Sex differences in human behaviour, personality and tendency to emotional states are well documented, and research on sex differences has found that boys/men engage in more dominance-seeking behaviour (1-3), are more involved in risk-taking (4) and are less prone to depression or low self-esteem than girls/women (5). It is assumed that androgens, in particular testosterone, may play a role in the aetiology of aggression $(6-8)$, non-aggressive forms of adolescent risk-taking $(9,10)$ and, at least in hypogonadal men, mood-related variables such as depression or self-esteem (11-13). However, results have been inconsistent, with most studies finding at best small or moderate associations with androgens, often in clinical or atypical populations, e.g. hypogonadal men/boys.

Despite the recognition that serum levels of testosterone are only one aspect of the androgen cascade that plays a role in the aetiology of sex-dimorphic traits and behaviours $(14,15)$, a limited number of studies have analyzed the role of other factors (among them, genetic factors) that may modify testosterone action with respect to behaviour. Androgens bind to intracellular receptors, and as such, these intracellular receptors moderate androgen-related changes in gene expression. The androgen receptor (AR) gene is located on the $\mathrm{X}$ chromosome at XQ11-12 and is highly polymorphic, and research has identified at least 200 mutations in patients with androgen insensitivity syndrome (16). More subtle modulations of the transcriptional activity induced by the AR have been assigned to a polyglutamine stretch of variable length within the N-terminal domain of the receptor encoded by a polymorphic CAG repeat in the first exon of the AR gene. In a normal population, this triplet is repeated 9-37 times $(17,18)$. Reduction in androgen gene expression is thought to be proportional to the number of CAG repeats over the range of normal alleles, with the shorter alleles showing the greatest activity (16). Studies indicating that a lower number of CAG repeats is associated with androgen-dependent conditions, e.g. prostate cancer (19), benign prostate hyperplasia (20) and higher incidence of alopecia (21), support this finding. However, not all studies have found such associations $(18,22)$.

If both androgen serum levels and AR sensitivity are aspects of the androgen cascade, it may be important to assess both serum levels of testosterone and CAG repeat length, and to analyze the possible interactions between 
the two. Some studies have already documented these interactions. It was found, for example, that the AR gene CAG polymorphism contributed modestly to the between-subject variation in testosterone action on body composition in community-dwelling elderly individuals (23). In addition, it has been shown that the CAG repeat polymorphism modulates responses induced by testosterone replacement therapy in hypogonadal men $(24,25)$.

It has been proposed that CAG repeat length may be relevant with respect to explaining androgen-related behaviours as well. Several studies in humans have found that the presence of shorter alleles of the AR gene was related to attention deficit hyperactivity disorder (ADHD), conduct disorder and oppositional defiant disorder (26) and to violent criminal behaviour (27). Others found that the relationship with criminal activity was small at best (28). Evidence of a relationship between CAG repeat length and personality traits has been inconsistent as well, with some studies finding that AR was related to personality traits such as Eysenck's psychoticism (29), while others found no such association (30) or found tendencies for an inverse association (31) in boys.

Studies on the existence of interactions between CAG repeat length and testosterone with respect to sexdimorphic behaviour or traits, however, are scarce. One study of middle-aged men showed depressive symptoms to be inversely associated with total testosterone (TT) in men with shorter CAG repeat lengths, but not in men with moderate and longer CAG repeat lengths (32).

In this study we have analyzed, in a sample of adolescent boys of Caucasian origin, the interactions between testosterone and CAG repeat length polymorphism as a modulator of AR sensitivity with respect to adolescent risk-taking and aggression, dominance, symptoms of depressive symptoms and self-esteem. These traits and behaviours were selected because they have well-documented sex differences, and because evidence exists on the relationship between testosterone and these traits and behaviours.

\section{Methods}

\section{Subjects}

Data presented in this paper are part of ADORISK, which is a larger study on the social and biological determinants of the sex gap in adolescent risk-taking. The target group of this study was the population of third-grade secondary school students (average age 14-15 years). The project was set up in collaboration with the Belgian Centres for Pupil Coaching (CPCs), which are associated with public authority schools and private schools. Four CPCs in four Flemish cities hosted the data collection. All third-grade students attending a routine medical consultation at the CPCs were given the opportunity to participate in the research project in exchange for an incentive. Only students who had given their full written consent, and whose parents had given their full consent, were allowed to participate. The ethics committee of the University Hospital of Ghent (Belgium) approved informed consent letters and privacy guarantees. Seventy-one percent of the eligible students participated, resulting in a total sample of 301 boys and 298 girls. This paper focuses on the sample of boys. A comparison between the distribution of the adolescents in the Flemish third-grade population and in this study's sample across the different tracks of the educational system - general, technical, vocational and art education - showed that the latter sample was relatively well balanced. Detailed information on the study design can be found in earlier publications (10).

\section{Operationalization and measurement}

Independent variables Hormone assays. Blood samples were collected by a nurse, and were frozen at $-80^{\circ} \mathrm{C}$ until assay. All blood samples were collected between 0900 and $1130 \mathrm{~h} ; 70.8 \%$ were collected before $1000 \mathrm{~h}$. An ANOVA on boys showed no significant difference in $\mathrm{TT}$, total oestradiol $\left(\mathrm{TE}_{2}\right)$ and sex hormone-binding globulin (SHBG) samples collected both before and after $1000 \mathrm{~h}$.

Commercial immunoassays were used to determine serum concentrations of TT (Orion Diagnostica, Espoo, Finland) and SHBG (Orion Diagnostica). The assay sensitivity for TT was $10 \mathrm{ng} / \mathrm{dl}$; the intra-assay coefficient of variation (CV) fell between 4.6 and $10.1 \%$, and the inter-assay $\mathrm{CV}$ fell between 5.2 and $11.7 \%$. The sensitivity for SHBG was $0.7 \mathrm{nmol} / \mathrm{l}$; the intra-assay CV fell between 2.6 and $8.5 \%$, and the inter-assay CV fell between 3.4 and $9.6 \%$. The sensitivity for $\mathrm{TE}_{2}$ was $0.2 \mathrm{ng} / \mathrm{dl}$; the intra-assay CV was $3 \%$ and the inter-assay CV was $8.55 \%$.

Free testosterone $(\mathrm{FT})$ and free oestradiol $\left(\mathrm{FE}_{2}\right)$ were calculated from total hormone SHBG and albumin concentrations by means of validated equations derived from the mass action law (33). We used FT in the analyses rather than $\mathrm{TT}$, as it is the unbound testosterone that binds to the ARs.

CAG repeat length. Genomic DNA was extracted from EDTA-treated blood using a commercial kit (Qiagen Midi kit, Qiagen Inc). We used PCR to amplify exon 1 of the AR gene with primers $5^{\prime}$-AGCCTGTTGAACTCTTCTGAGC-3' (sense) and 5'-CTGCCTTACACAACTCCTTGGC-3' (antisense). After ethanol precipitation, the amplified fragment was directly sequenced on a ABI Prism 310 sequencer (ABI Prism, Perkin-Elmer Applied Biosystems, Foster City, CA, USA) using a BigDye Terminator Cycle Sequencing Reaction kit (ABI Prism, Perkin-Elmer Applied Biosystems). Fragment length was determined by running the GeneScan-400HD Analysis Software (ABI Prism, Perkin-Elmer Applied Biosystems). 
Dependent variables Adolescent risk-taking. Aggressive risk-taking (ART) and non-aggressive risk-taking (NART) scales were developed and validated by confirmatory factor analysis as part of the ADORISK project (full scales included in 10).

To measure ART, we asked our respondents to rate their experience, with six items on a 5-point scale. Items included actual physical aggression (I was involved in fighting at school), threats of violence (I threatened someone with violence) or verbal aggression (I insulted a teacher to his/her face). Cronbach's $\alpha$ for this scale was 0.79 , with the corrected item-total correlations between 0.38 and 0.65 . To measure NART, we asked our respondents to rate their experience, with 21 items on a 5-point scale. Items included, e.g. 'I smoked a joint', 'I took a train, tram or bus without paying' and 'I drank five glasses of alcohol in one evening'. Cronbach's $\alpha$ for this scale was 0.88 , with the corrected item-total correlations ranging between 0.38 and 0.66 .

Dominance. To measure dominance, respondents were asked to complete the California Psychological Inventory-Dominance (CPI-D) scale. The CPI-D scale (34) consists of 11 items to be rated on a 5 -point scale. Items include 'I try to surpass others' accomplishments', 'I want to control the conversation' and 'I put people under pressure'. Cronbach's $\alpha$ for this scale was 0.83 , with the corrected item-total correlations ranging between 0.38 and 0.61 . The sum of the item scores was used.

Depressive symptoms. To measure depressive symptoms, we used the Centre for Epidemiologic Studies-Depression (CES-D) questionnaire (35). The CES-D questionnaire is an often-used and validated instrument (36-38) that consists of 20 items to be rated on a 4-point scale. The Dutch translation of this scale (39) has good reliability and validity. Cronbach's $\alpha$ was 0.88 , with the corrected item-total correlations ranging between 0.35 and 0.69. The sum of the item scores was used.

Self-esteem. To measure self-esteem, we used a Dutch self-esteem scale (40) that is largely based on the Rosenberg self-esteem scale (41), and that has been adapted to the Flemish context. The scale consists of 12 items to be rated on a 5-point scale. Cronbach's $\alpha$ was 0.88 , with the corrected item-total correlations ranging between 0.42 and 0.70 . The sum of the scores was used.

Control variables Pubertal development. Pubertal development (PD) was measured by the Tanner stage (42) and assessed by a physician. Scores were assessed based on both pubic hair and pubis development, using a scale of 1 (prepubertal) to 5 (adult). Scores were totalled, resulting in an index of 2-10.

Age. Age was measured as 'years completed at the time of the research'. Age is especially important, as previous analyses have indicated that the effect of testosterone on risk-taking (non-aggressive and aggressive forms) is more pronounced in older boys than in younger boys; therefore, age $\mathrm{X}$ testosterone interactions were included in the analyses.

Ethnicity. Ethnic differences have been reported in average CAG repeat lengths. In our sample, 18 individuals were not of European Caucasian origin (operationalized as having at least one parent of nonEuropean ancestry). This group is too small and too diverse to allow for separate analyses. For this reason, and because differences in cultural background could affect the dependent variables, our study, like other studies (43), removed individuals of non-Caucasian ancestry $(n=18)$ from the analyses.

Table 1 Characteristics of the sample $(n=283)$.

\begin{tabular}{|c|c|c|c|c|c|}
\hline & Mean & S.D. & $\begin{array}{l}\text { Observed } \\
\text { minimum }\end{array}$ & $\begin{array}{l}\text { Observed } \\
\text { maximum }\end{array}$ & $\begin{array}{l}\text { Normal range } \\
\text { (adult men) }^{\mathrm{a}}\end{array}$ \\
\hline Age & 14.4 & 0.74 & 13 & 18 & \\
\hline PD & 8.38 & 1.9 & 2 & 10 & \\
\hline TT & 371 & 161.98 & 13.60 & 888.30 & $321-1005$ \\
\hline $\mathrm{TE}_{2}$ & 14.74 & 4.85 & 5.49 & 36.84 & $13.14-31.34$ \\
\hline SHBG & 35.75 & 19.16 & 4.93 & 137.92 & $10.04-59.5$ \\
\hline $\mathrm{FT}(\mathrm{ng} / \mathrm{dl})$ & 8.03 & 4.17 & 0.17 & 20.01 & $6-25$ \\
\hline $\mathrm{FE}_{2}$ & 0.27 & 0.12 & 0.05 & 0.79 & $0.26-0.63$ \\
\hline CAG RL & 21.76 & 3.06 & 12 & 35 & $9-37^{b}$ \\
\hline Body fat $(\%)$ & 12.83 & 6.09 & 2.60 & 37.30 & \\
\hline NART & 39.62 & 9.8 & 23 & 72 & \\
\hline ART & 11.11 & 3 & 6 & 21 & \\
\hline Dominance & 30.05 & 7.27 & 15 & 45 & \\
\hline CES-D & 29.88 & 5.30 & 20 & 60 & \\
\hline Self-esteem & 43.52 & 6.64 & 26 & 60 & \\
\hline
\end{tabular}

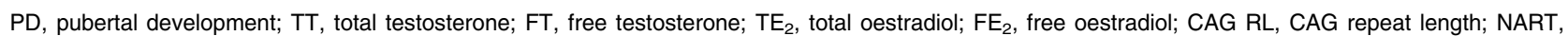
non-aggressive risk-taking; ART, aggressive risk-taking; CES-D, depressive symptoms.

${ }^{a}$ Reference values as indicated by commercial immunoassay kits.

' Zitzmann \& Nieschlag (2003). 
Body fat percentage. Body fat may be related to CAG repeat length, and hormonal values may be associated with body fat $(44,45)$. Body fat percentage was measured by a nurse using leg-to-leg bioimpedance equipment (TBF-300, Tanita Arlington Heights, IL, USA).

Lifestyle factors. SHBG and unbound, bioactive testosterone may be influenced by lifestyle factors such as smoking and alcohol consumption (46) and, as such, their relationship with risk-taking and/or any of the mood-related dependent variable may be modified. Smoking and regular alcohol consumption are items that are included in the NART scale, and are as such strongly related to this scale. These variables cannot be easily controlled for as this would strongly increase multicollinearity. However, we controlled for alcohol consumption during the day prior to the study as a binary variable, with ' 0 ' indicating 'no consumption' and ' 1 ' indicating 'consumption' of alcohol.

\section{Analyses}

To analyze the relationships between independent and dependent variables, we used multivariate general linear modelling. This technique analyzes the relationship of each predictor variable, and the dependent variables, controlling for all other predictor variables, but also controls for the relationships among the multiple dependent variables.

Analyses were done using three models. In the first model, independent variables without interactions were introduced. In the second model, interaction terms were introduced. To avoid high levels of multicollinearity, independent variables were standardized before product terms were calculated. The effect of $\mathrm{FE}_{2}$ was controlled for only in the third model to avoid a potential problem of multicollinearity: $\mathrm{FT}$ and $\mathrm{FE}_{2}$ are strongly associated, and this may reduce the possibility of differentiating statistically between the effects of FT and $\mathrm{FE}_{2}$. Although variance inflation factor (VIF) scores in the analyses that include $\mathrm{FE}_{2}$ are moderate and do not exceed 3.05, multicollinearity may inflate the s.E.M. and affect the levels of significance. As such, differences between the results of the second and the third models should be interpreted with care. For this reason, we used an analysis in which FT was regressed on $\mathrm{FE}_{2}$ and the standardized residuals were calculated. These residuals - that reflect the variability in $\mathrm{FE}_{2}$ once $\mathrm{FT}$ is controlled for - were then substituted for $\mathrm{FE}_{2}$ in the analyses presented in the third model. The results of this additional analysis were compared with the results obtained using the third model.

Although CAG repeat length was used as a continuous variable in the analysis, to depict interaction effects, it was categorized by taking the mean repeat length (21.69) \pm 0.5 S.D. (3.03), resulting in short $(\leq 20 ; n=94)$, medium $(>20$ and $\leq 23 ; n=115)$ and long $(>23 ; n=71)$ CAG repeat lengths. Because using

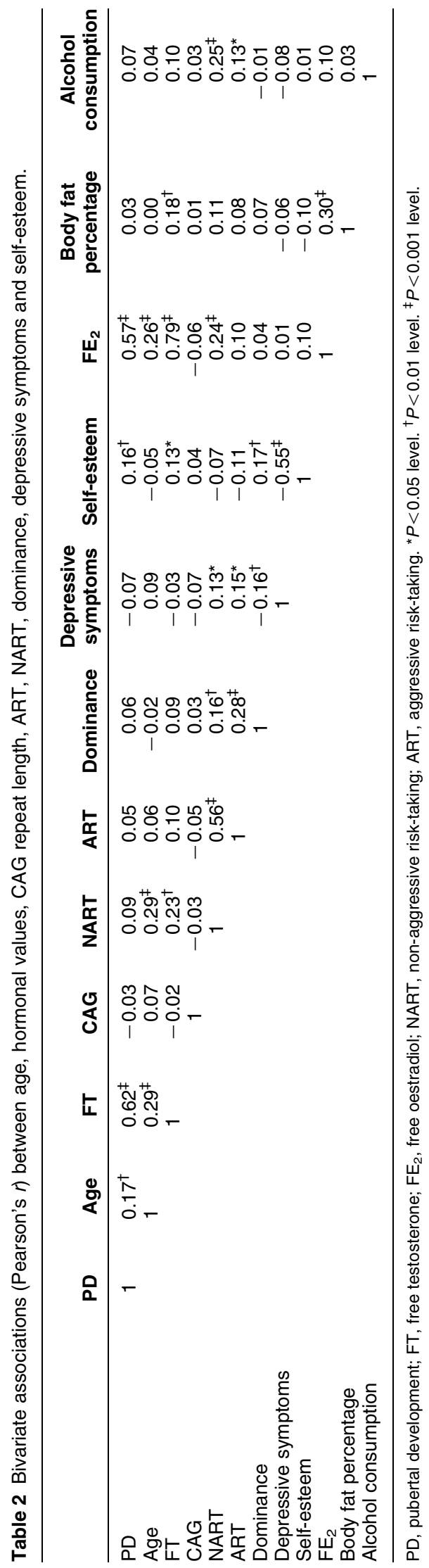

www.eje-online.org 


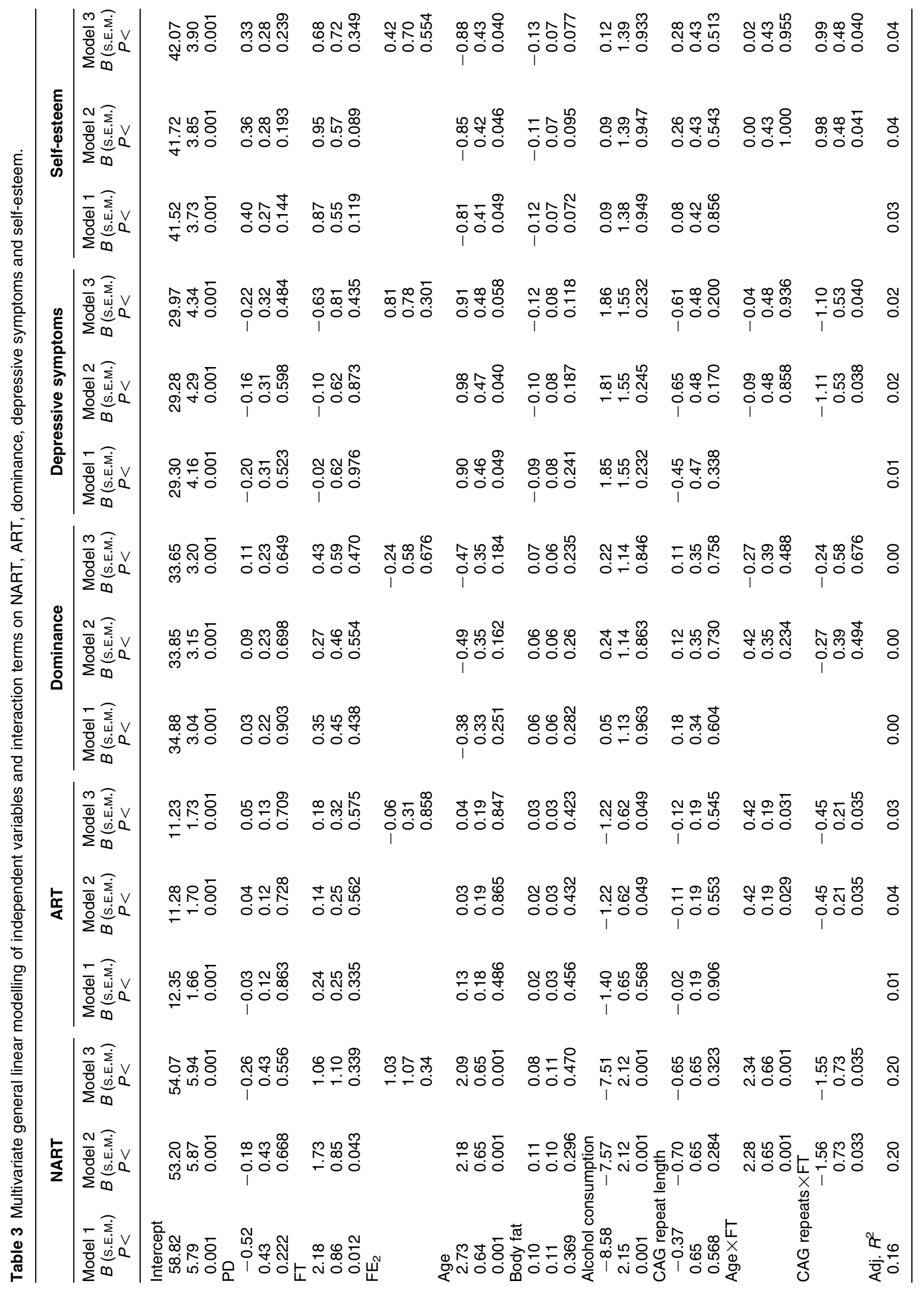


1 s.D. would have resulted in the 'short' category having an insufficient number of cases $(n=35)$ to analyze, 0.5 S.D. was used. Cut-off values used were similar to those used by others (44). Alternative classifications using the 33th and 66th percentiles did not yield visualizations that were substantially different from those presented in this paper.

Missing values were present with respect to PD $(n=11)$, CAG repeats $(1), \mathrm{NART}=3$, ART $(n=2)$, dominance $(n=1)$, CES-D $(n=1)$ and self-esteem $(n=1)$.

\section{Results}

\section{Univariate analyses}

Table 1 shows the results of univariate analyses. The mean age was 14.4 years (s.D. $=0.74$ ). The mean PD was 8.38 (s.D. $=1.9$ ), and the average mean for TT, SHBG and FT was within the normal range for adult men. The mean CAG repeat length was comparable to what other studies on individuals of Caucasian origin found (14). In total, 9.4\% of the participants (data not shown in Table 1) reported to have drunk alcohol on the day prior to the study.

\section{Bivariate analyses}

Table 2 shows the results of bivariate analyses. FT was related to NART $(r=0.23 ; P<0.001)$ and self-esteem $(r=0.13 ; P<0.05)$, but not to dominance or ART. CAG repeat length was unrelated to NART, ART or dominance. FT was related to age $(r=0.23 ; P<0.001)$ and PD $(r=0.61 ; P<0.001)$. PD was related to self-esteem $(r=0.16 ; P<0.01) . \mathrm{FE}_{2}$ was related to FT $(r=0.79 ; P<0.001)$ and NART $(r=0.24 ; P<0.01)$. Body fat was related to FT $(r=0.18 ; P<0.01)$ and $\mathrm{FE}_{2}$ $(r=0.30 ; P<0.001)$. Alcohol consumption on the day prior to the study was related to NART $(r=0.25$; $P<0.001)$ and ART $(r=0.13 ; P<0.05)$.

\section{Multivariate analyses}

Table 3 shows the results of the multivariate analyses. In the first step, the main effect of the independent variables was assessed. NART was related to age (B: 2.73; $P<0.001)$ and FT $(B: 2.18 ; P<0.012)$, but not to any of the other dependent variables. CAG repeat length was not associated with any of the dependent variables.

In the second step, we tested whether CAG repeat length moderated the relationship between FT and dependent variables. Significant interaction effects were found with respect to NART $(B=-1.56 ; P<0.033)$ and ART $(B=-0.45 ; P<0.035)$, indicating that the effect of FT on NART and ART was more pronounced in boys with shorter CAG repeat lengths. While in the strictest sense, no interaction effect between FT and CAG

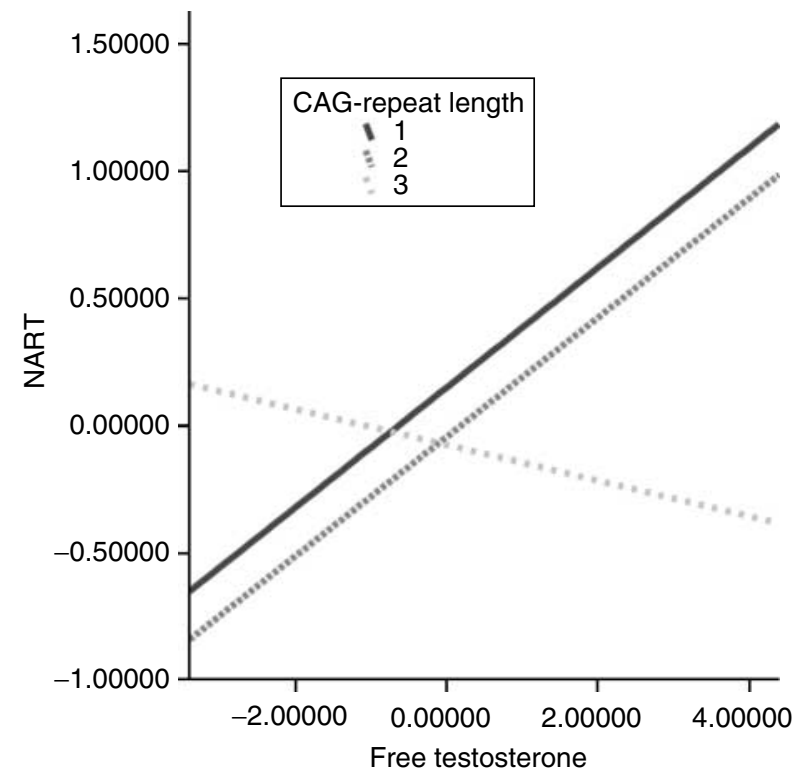

Figure 1 Testosterone and non-aggressive risk-taking (NART) in boys with i) short $(\leq 20)$, ii) medium $(>20$ and $\leq 23$ ) and iii) long $(>23)$ CAG repeat lengths.

repeat length was found with respect to dominance, Fig. 3 hints that a relationship between FT and dominance may exist in the short CAG repeat length group, but not in the other groups. Using the categorization outlined in Methods section, a multivariate linear regression (not shown in tables) in the short CAG repeat length category, controlling for age and PD, confirmed an effect of FT $(B=1.62 ; P>0.028)$

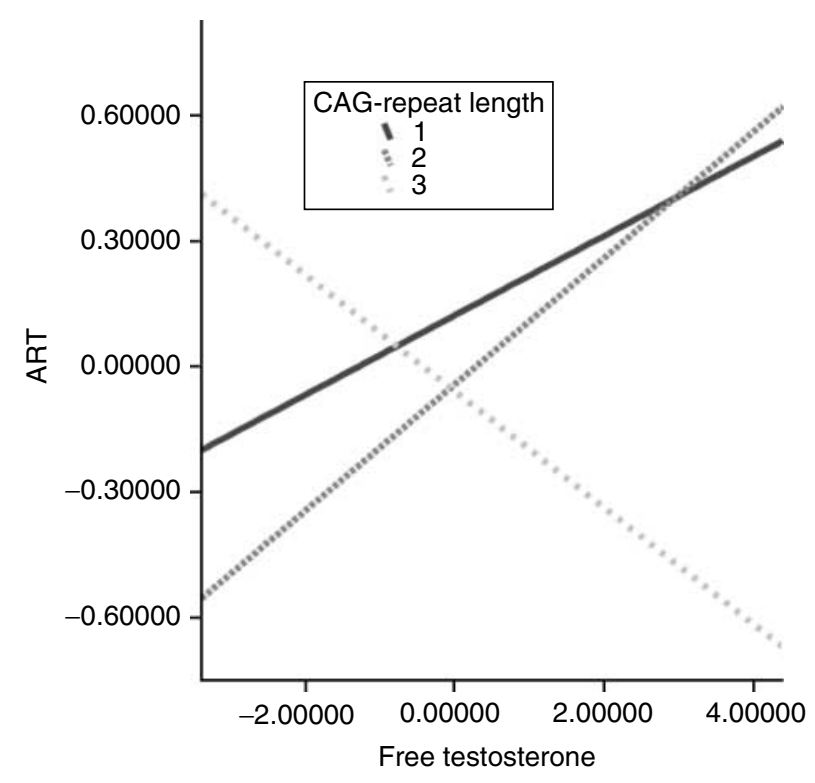

Figure 2 Testosterone and aggressive risk-taking (ART) in boys with i) short $(\leq 20)$, ii) medium ( $>20$ and $\leq 23)$ and iii) long $(>23)$ CAG repeat lengths. 
that was absent in the medium $(B=0.02 ; P<0.969)$ and the long $(B=-0.15 ; P<0.892) C A G$ repeat length categories. However, the effect of FT may not be strong enough when using CAG repeat length as a continuous variable to be translated into an interaction effect.

In addition, significant interaction effects were found between FT and $\mathrm{CAG}$ repeat length with respect to depressive symptoms $(B=-1.11 ; P<0.038)$ and selfesteem $(B=0.98 ; P<0.041)$, indicating that in boys with long CAG repeat lengths, FT was more strongly and negatively associated with depressive symptoms and more strongly and positively associated with selfesteem. Figures 1-5 depict the interaction effects.

As reported in an earlier study (10), a significant interaction was found between age and FT with respect to NART $(B=2.28 ; P<0.001)$ and ART $(B=0.42$; $P<0.029$ ), indicating that the effect of FT on ART and NART was more pronounced in older boys. No other significant interactions were found.

In the third step, the analyses were presented, controlling for $\mathrm{FE}_{2}$. $\mathrm{FE}_{2}$ was not related to any of the dependent variables. While the direct effect of FT with respect to NART was attenuated and was no longer significant $(B=1.06 ; P<0.339)$, the interaction between $\mathrm{CAG}$ repeat length and FT with respect to NART, ART, depressive symptoms and self-esteem remained significant. Replacement of $\mathrm{FE}_{2}$ with the standardized residuals obtained from regressing FT on $\mathrm{FE}_{2}$ (see Methods) did not result in substantially different results in this model, except for the finding that the direct effect of FT on NART remained significant $(B=1.87 ; P<0.031$; data not shown).

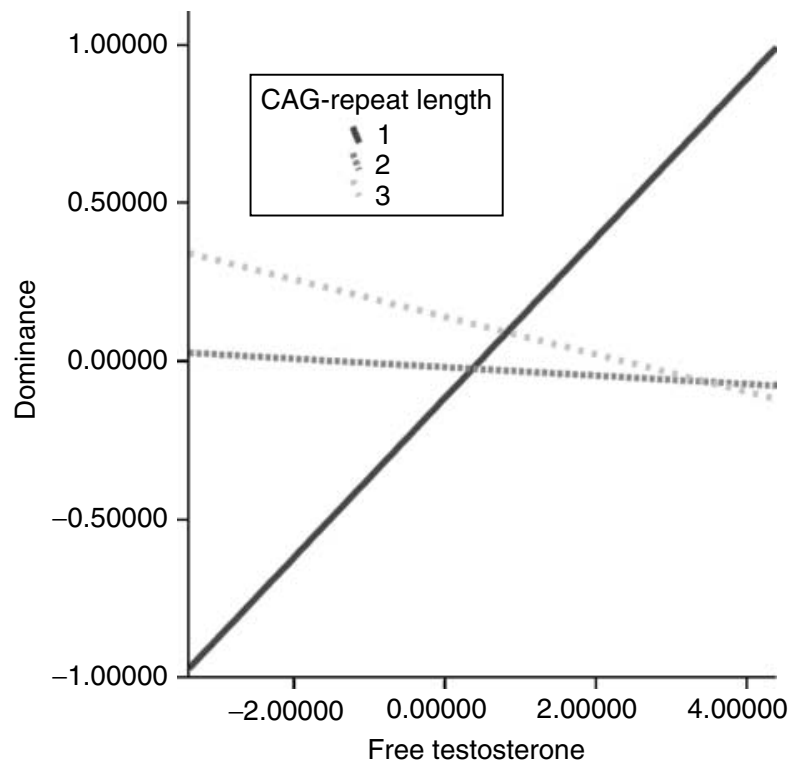

Figure 3 Testosterone and dominance in boys with i) short $(\leq 20)$, ii) medium ( $>20$ and $\leq 23$ ) and iii) long $(>23)$ CAG repeat lengths.

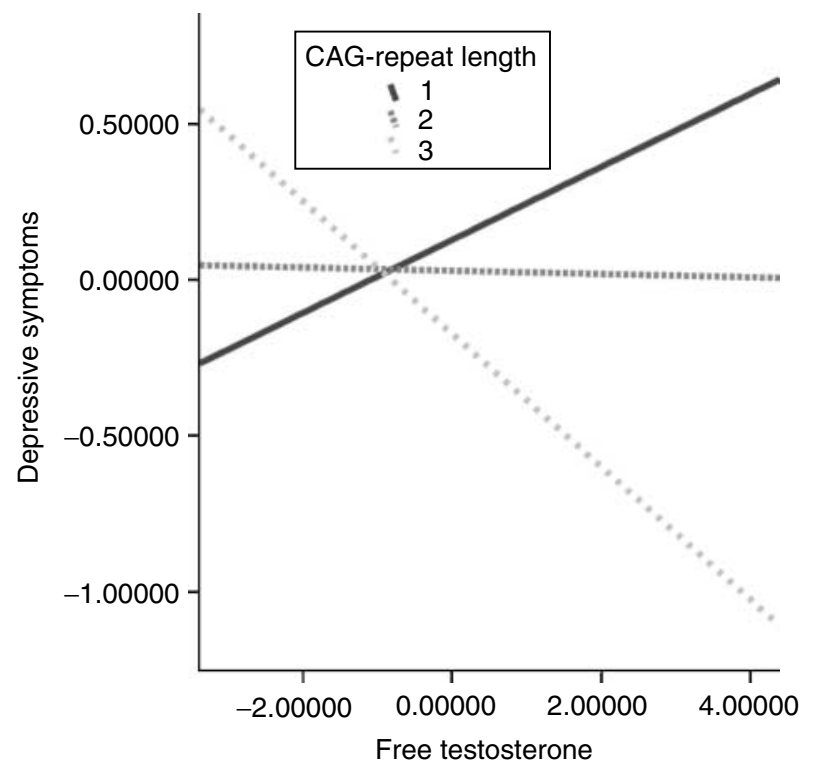

Figure 4 Testosterone and depressive symptoms in boys with i) short $(\leq 20)$, ii) medium ( $>20$ and $\leq 23$ ) and iii) long ( $>23)$ CAG repeat lengths.

\section{Conclusion and discussion}

In this paper, we analyzed the relationship between AR sensitivity and testosterone in a sample of adolescent boys. The mean CAG repeat length was 21.76, and is comparable to the number of CAG repeats in healthy Caucasians as reported in other studies (14).

In multivariate analyses, FT was related to NART but not to any of the other dependent variables. Unlike some studies $(26,27,29)$, but consistent with other studies $(28,30)$, we found that CAG repeat length in itself - at least in adolescent boys - was not a direct correlate of behaviour or other traits. However, our analyses do not indicate that CAG repeat length is irrelevant with respect to sex-dimorphic traits and behaviours. We found interactions between FT and CAG repeat length, showing that FT is more strongly related to nonaggressive and aggressive risk-taking in boys with shorter CAG repeat lengths. We also found interactions between FT and CAG repeat length with respect to depressive symptoms and self-esteem, indicating that FT is negatively associated with depressive symptoms and self-esteem in boys with longer CAG repeat lengths. In addition, we found that FT is significantly related to dominance in boys with short CAG repeat lengths, but not to that in boys with medium or long CAG repeat lengths. $\mathrm{FE}_{2}$ and body fat were unrelated to any of the dependent variables. Alcohol consumption on the day prior to the study was related to NART and ART, but not to $\mathrm{FE}_{2}$ or FT.

Our findings are among the first to document this theoretically relevant interaction. These results and previous observations $(14,15,23-25,32)$ support the 


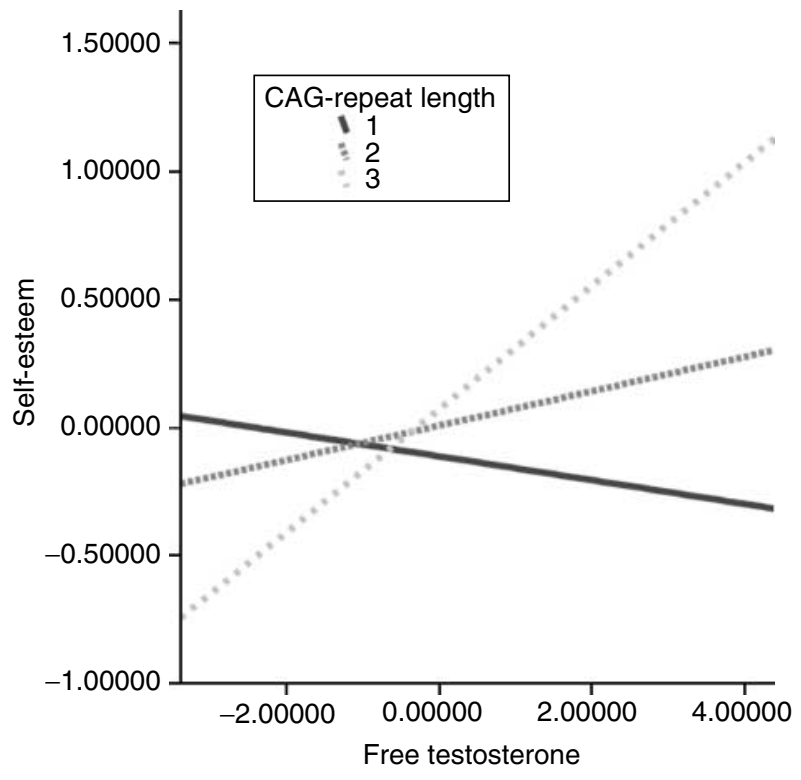

Figure 5 Testosterone and self-esteem in boys with i) short $(\leq 20)$, ii) medium ( $>20$ and $\leq 23$ ) and iii) long $(>23)$ CAG repeat lengths.

concept that serum testosterone and indicators of AR sensitivity should be studied simultaneously with respect to sex-dimorphic traits and behaviours.

The finding that androgens affect mood mostly in hypogonadal males and rarely in eugonadal males may be consistent with our results that indicate that the effect of FT on depressive symptoms and self-esteem mood was stronger in boys with long CAG repeat lengths. Another study (32), however, found that in middle-aged men, depression was significantly and inversely associated with TT in men with shorter CAG repeat lengths, but not with that in men with moderate and longer CAG repeat lengths. A direct comparison between the results presented here and the results from that study is complicated, as the study populations are markedly different in age and average testosterone levels.

There is no theory at hand to explain our finding that the interaction effects with respect to depressive symptoms and self-esteem are different from the interaction effects we found with respect to the behavioural variables. While FT may affect moodrelated and behavioural variables differently depending on AR sensitivity, further research should analyse the complex dynamics between CAG repeat length and FT (including potential compensatory mechanisms between the two) to explain this finding.

Several factors may further hinder the interpretation of the results. First, the study design is cross-sectional; as a result, conclusions only about associations and not about causation can be drawn. Secondly, CAG repeat length is not the only genetic factor involved in AR sensitivity: e.g. the polyglycine tract encoded by a polymorphic GGN repeat in exon 1 of the AR might have some modulatory effects $(48,49)$; a number of co-activators and co-repressors might further have major, tissue-specific modulating effects on AR transactivation $(16,50)$. In addition, further research should try to control i) for lifestyle-related factors such as smoking, diet and physical activity, and ii) for other non-hormone-related factors such as the social environment in which adolescents act, as both may change the relationships between hormones and mood-related or behavioural outcomes.

The variance explained by the interaction between testosterone and CAG repeat length with respect to depressive symptoms and self-esteem is limited. It may not represent a mechanism that contributes much to the variability in depressive symptoms or self-esteem in a normal population of adolescent boys. The literature suggests that in this respect, the effect of testosterone administration on mood may be present in hypogonadal males, but may be less present in eugonadal males (50). In eugonadal males, other individual traits or characteristics of the social environment in which adolescents act may be much more important with respect to depressive symptoms and/or self-esteem.

In summary, in a sample of adolescent boys, using a multivariate design, we found i) no direct relationship between CAG repeat length and risk-taking or dominance, ii) interactions between testosterone and CAG repeat length with respect to NART, ART, depressive symptoms and self-esteem.

\section{Declaration of interest}

The authors declare that there is no conflict of interest that could be perceived as prejudicing the impartiality of the research reported.

\section{Funding}

This work was supported by the FWO (Foundation for Scientific Research, Flanders), grant number 31514609.

\section{References}

1 Feingold A. Gender differences in personality: a meta-analysis. Psychological Bulletin 1994116 429-456.

2 Luxen MF. Gender differences in dominance and affiliation during a demanding interaction. Journal of Psychology 2005139 331-347.

3 Maccoby EE \& Jacklin CN. The Psychology of Sex Differences. Stanford: Stanford University Press, 1974.

4 Byrnes JP, Miller DC \& Schaffer WD. Gender differences in risk-taking: a meta-analysis. Psychological Bulletin 1999125 367-383.

5 Kessler RC, McGonagle KA, Swartz M, Blazer DG \& Nelson CB. Sex and depression in the National Comorbidity Survey, I: lifetime prevalence, chronicity and recurrence. Journal of Affective Disorders 199329 85-96.

6 Aromaki AS, Lindman RE \& Eriksson CJP. Testosterone, aggressiveness, and antisocial personality. Aggressive Behavior 199925 $113-123$. 
7 Tremblay RE, Schaal B, Boulerice B, Arsenault L, Soussignan RG, Paquette D \& Laurent D. Testosterone, physical aggression, dominance, and physical development in early adolescence. International Journal of Behavioral Development 199822 753-777.

8 Finkelstein JW, Susman EJ, Chinchilli VM, Knuselman SJ, Darcangelo MR, Schwab J, Demers LM, Liben LS, Lookingbill G \& Kulin HE. Estrogen or testosterone increases self-reported aggressive behaviors in hypogonadal adolescents. Journal of Clinical Endocrinology and Metabolism 199782 2433-2438.

9 Rowe R, Maughan B, Worthman CM, Costello EJ \& Angold A. Testosterone, antisocial behavior, and social dominance in boys: pubertal development and biosocial interaction. Biological Psychiatry 200455 546-552.

10 Vermeersch H, T'Sjoen G, Kaufman JM \& Vincke J. The role of testosterone in aggressive and non-aggressive risk-taking in adolescent boys. Hormones and Behavior 200853 463-471.

11 O'Connor DB, Archer J, Hair WH \& Wu FCW. Exogenous testosterone, aggression, and mood in eugonadal and hypogonadal men. Physiology and Behavior 200175 557-566.

12 Anderson RA, Martin CW, Kung AWC, Everington D, Pun TC, Tan KCB, Bancroft J, Sundaram K, Moo-Joung AJ \& Baird DT. $7 \alpha$-Methyl-19-nortestosterone maintains sexual behavior and mood in hypogonadal men. Journal of Clinical Endocrinology and Metabolism 199984 3556-3562.

13 Wang C, Swerdloff RS, Iranmanesh A, Dobs A, Snyder PJ, Cunningham G, Matsumoto AM, Weber $\mathrm{T} \&$ Berman $\mathrm{N}$. Transdermal testosterone gel improves sexual function, mood, muscle strength, and body composition parameters in hypogonadal men. Journal of Clinical Endocrinology and Metabolism $2000 \mathbf{8 5}$ 2839-2853.

14 Zitzmann M \& Nieschlag E. The CAG repeat polymorphism within the androgen receptor gene and maleness. International Journal of Andrology 200326 76-83.

15 Crabbe P, Bogaert V, De Bacquer D, Goemaere S, Zmierczak H \& Kaufman JM. Part of the interindividual variation in serum testosterone levels in healthy men reflects differences in androgen sensitivity and feedback set point: contribution of the androgen receptor polyglutamine tract polymorphism. Journal of Clinical Endocrinology and Metabolism 20079 3604-3610.

16 Choong CS \& Wilson EM. Trinucleotide repeats in the human androgen receptor: a molecular basis for disease. Journal of Molecular Endocrinology 199821 235-257.

17 Hsing AW, Gao YT, Wu G, Wang X, Deng J, Chen YL, Sesterhenn IA, Mostofi K, Benichou J \& Chang C. Polymorphic CAG and GGN repeat lengths in the androgen receptor gene and prostate cancer risk: a population-based case-control study in China. Cancer Research $2000605111-5116$.

18 Platz EA, Leitzmann MF, Rifai N, Kantoff PW, Chen YC, Stampfer MJ, Willett WC \& Giovannucci E. Sex steroid hormones and the androgen receptor gene CAG repeat and subsequent risk of prostate cancer in the prostate-specific antigen era. Cancer Epidemiology, Biomarkers and Prevention 200514 1262-1269.

19 Stanford JL, Just JJ, Gibbs M, Wicklund KG, Neal CL, Blumenstein BA \& Ostrander EA. Polymorphic repeats in the androgen receptor gene: molecular markers of prostate cancer risk. Cancer Research 199757 1194-1198.

20 Giovannucci E, Platz EA, Stampfer MJ, Chan A, Krithivas K, Kawachi I, Willett WC \& Kantoff PW. The CAG repeat within the androgen receptor gene and benign prostatic hyperplasia. Journal of Urology 1999162 269-270.

21 Sawaya ME \& Shalita AR. Androgen receptor polymorphisms (CAG repeat lengths) in androgenetic alopecia, hirsutism and acne. Journal of Cutaneous Medicine and Surgery 1998 1 9-15.

22 Correa-Cerro L, Wöhr G, Häussler J, Berthon P, Drelon E, Mangin P, Fournier G, Cussenot O, Kraus P, Just W, Paiss T, Cantu JM \& Vogel W. (CAG)nCAA and GGN repeats in the human androgen receptor gene are not associated with prostate cancer in a French-German population. European Journal of Human Genetics $19997357-362$.
23 Lapauw B, Goemaere S, Crabbe P, Kaufman JM \& Ruige JB. Is the effect of testosterone on body composition modulated by the androgen receptor gene CAG repeat polymorphism in elderly men? European Journal of Endocrinology 2007156 395-401.

24 Zitzmann M, Depenbusch M, Gromoll J \& Nieschlag E. Prostate volume and growth in testosterone-substituted hypogonadal men are dependent on the CAG repeat polymorphism of the androgen receptor gene: a longitudinal pharmacogenetic study. Journal of Clinical Endocrinology and Metabolism 2003 88 2049-2054.

25 Zitzmann M \& Nieschlag E. Androgen receptor gene CAG repeat length and body mass index modulate the safety of long-term intramuscular testosterone undecanoate therapy in hypogonadal men. Journal of Clinical Endocrinology and Metabolism $2007 \mathbf{9 2}$ 3844-3853.

26 Comings DE, Chen C, Wu S \& Muhleman D. Associations of the androgen receptor gene (AR) with ADHD and conduct disorder. Neuroreport 19997 1589-1592.

27 Rajender S, Pandu G, Sharma JD, Ghandi KPC, Singh L \& Thangaraj K. Reduces CAG repeat length in androgen receptor gene is associated with violent criminal behavior. International Journal of Legal Medicine 2008122 367-372.

28 Cheng D, Hong CH, Liao DL \& Tsai SJ. Association study of androgen receptor CAG repeat polymorphism and male violent criminal activity. Psychoneuroendocrinology $200631548-552$.

29 Turakulov R, Jorm AF, Jacomb PA, Tan X \& Easteal S. Association of dopamine- $\beta$-hydroxylase and androgen receptor gene polymorphisms with Eysenck's $P$ and other personality traits. Personality and Individual Differences 200437 191-202.

30 Jönsson EG, von Gertten C, Gustavsson JP, Yuan QP, LindbladToh K, Forslund K, Rylander G, Mattila-Evenden M, Asberg M \& Schalling M. Androgen receptor trinucleotide repeat polymorphism and personality traits. Psychiatric Genetics 200111 19-23.

31 Loehlin JC, Medland SE, Montgomery GW \& Martin NG. Eysenck's psychoticism and the X-linked androgen receptor gene CAG polymorphism in additional Australian samples. Personality and Individual Differences $200539661-667$.

32 Seidman SN, Araujo AB, Roose SP \& McKinlay JB. Testosterone level, androgen receptor polymorphism, and depressive symptoms in middle-aged men. Biological Psychiatry $200150371-376$.

33 Vermeulen A, Verdonck L \& Kaufman JM. A critical evaluation of simple methods for the estimation of free testosterone in serum. Journal of Clinical Endocrinology and Metabolism $1999 \mathbf{8 4}$ 3666-3672.

34 Gough HG \& Bradley P. The California Psychological Inventory Manual. Palo Alto, CA: Consulting Psychologists Press, 1996.

35 Radloff LS. The CES-D scale: a self-report depression scale for research in the general population. Applied Psychological Measurement 19771 2-199.

36 Garrison CZ, Waller JL, Cuffe SP, McKeown RE, Addy CL \& Jackson KL. Incidence of major depressive disorder and dysthymia in young adolescents. Journal of the American Academy of Child and Adolescent Psychiatry 199736 458-465.

37 Dierker LC, Albano MB, Clarke GN, Heimberg RG, Kendall PC, Merikangas KR, Lewinsohn PM, Offord DR, Kessler R \& Kupfer DJ. Screening for anxiety and depression in early adolescence. Journal of the American Academy of Child and Adolescent Psychiatry 200140 929-936.

38 Okun A, Stein REK, Bauman LJ \& Silver EJ. Content validity of the psychiatric symptom index, CES-depression scale, and state-trait anxiety inventory from the perspective of DSM-IV. Psychological Reports 199679 1059-1069.

39 Bouma J, Ranchor AV \& Sanderman R. Assessment of Depressive Symptoms with the CES-D, Manual (in Dutch). Groningen: Noordelijk Centrum voor ezondheidsvraagstukken/Rijksuniversiteit, Groningen, 1995.

40 Brutsaert H. Co-educatie, Studiekansen en Kwaliteit van het Schoolleven. Antwerpen: Garant, 2001.

41 Rosenberg M. The Measurement of Self-esteem in Society and the Adolescent Self-image. Princeton: University Press, 1965. 
42 Tanner JM. Growth at Adolescence: With a General Consideration of the Effects of Hereditary and Environmental Factors upon Growth and Maturation from Birth to Maturity. Oxford: Blackwell Scientific Publications, 1962.

43 Hickey T, Chandy A \& Norman RJ. The androgen receptor CAG repeat polymorphism and X-chromosome inactivation in Australian Caucasian women with infertility related to polycystic ovary syndrome. Journal of Clinical Endocrinology and Metabolism 200287 161-165.

44 Zitzmann M, Gromoll J, von Eckardstein A \& Nieschlag E. The CAG repeat polymorphism in the androgen receptor gene modulates body fat mass and serum concentrations of leptin and insulin in men. Diabetologia 200346 31-39.

45 Segal KR, Dunalf A, Gutin B, Albu J, Nyman A \& Pi-Sunyer FX. Body composition, not body weight is related to cardiovascular disease risk factors and sex hormone levels in men. Journal of Clinical Investigation 198780 1050-1055.

46 Suzuki R, Allen NE, Appleby PN, Key TJ, Dossus L, Tjonneland A, Johnsen NF, Overvad K, Sacerdote C, Palli D, Krogh V, Tumino R, Rohrmann S, Linseisen J, Boeing H, Trichopoulou A, Makrygiannis G, Misirli G, Bueno-de-Mesquita HB, May AM, Diaz MJ, Śnchez MJ, Barricarte Gurrea A, Rodríguez Súrez L, Buckland G, Larrañaga N, Bingham S, Khaw KT, Rinaldi S, Slimani N, Jenab M, Riboli E \& Kaaks R. Lifestyle factors and serum androgens among 636 middle aged men from seven countries in the European Prospective Investigation into Cancer and Nutrition (EPIC). Cancer Causes and Control 200920 811-821.

47 Zitzmann M, Depenbusch M, Gromoll J \& Nieschlag E. X-chromosome inactivation patterns and androgen receptor functionality influence phenotype and social characteristics as well as pharmacogenetics of testosterone therapy in Klinefelter patients. Journal of Clinical Endocrinology and Metabolism 200489 6208-6217.

48 Westberg L, Henningsson S, Landen M, Annerbrink K, Melke J, Nilsson S, Rosmond R, Holm G, Anckarsater H \& Eriksoon E. Influence of androgen receptor repeat polymorphisms on personality traits in men. Journal of Psychiatry and Neuroscience 200934 205-213.

49 Bogaert V, Vanbillemont G, Taes Y, De Bacquer D, Deschepper E, Van Steen K \& Kaufman JM. Small effect of the androgen receptor gene GGN repeat polymorphism on serum testosterone levels in healthy men. European Journal of Endocrinology 2009161 171-177.

50 Zitzmann M \& Nieschlag E. Testosterone levels in healthy men and the relation to behavioural and physical characteristics: facts and constructs. European Journal of Endocrinology 2001 144 183-197.

Received 14 April 2010

Accepted 17 May 2010 